\title{
Using tethered-personal health records for pre- liminary end-of-life discussions with medical providers: Preferences of African American vs. Caucasian primary care patients
}

\author{
Seuli Bose-Brill ${ }^{1}$, Matthew Kretovics ${ }^{1}$, Taylor Ballenger ${ }^{1}$, Gabriella Modan $^{2}$, Albert Lai ${ }^{3}$, Lindsay \\ Belanger $^{4}$, Stephen Koesters ${ }^{1}$, J. Randall Curtis ${ }^{5}$, Celia Wills ${ }^{6}$ \\ 1. Division of General Internal Medicine, Department of Internal Medicine, College of Medicine, Ohio State University, \\ Columbus, OH, U.S.A. 2. Department of English, Ohio State University, Columbus, OH, U.S.A. 3. Department of \\ Biomedical Informatics, Ohio State University, Columbus, OH, U.S.A. 4. Boston University School of Public Health, Boston, \\ MA, U.S.A. 5. Palliative Care Center of Excellence, Pulmonary and Critical Care Medicine, Harborview Medical Center, \\ University of Washington, Seattle, WA, U.S.A. 6. College of Nursing, Ohio State University, Columbus, Ohio, U.S.A.
}

Correspondence: Seuli Bose-Brill. Address: Division of General Internal Medicine, Department of Internal Medicine, College of Medicine, Ohio State University, 1609 Northwest Blvd. Columbus, OH 43212, U.S.A.

Email: Seuli.Brill@osumc.edu

Received: October 14, 2013

Accepted: March 24, 2014

Online Published: April 18, 2014

DOI : $10.5430 /$ cns.v2n2p133

URL: http://dx.doi.org/10.5430/cns.v2n2p133

\begin{abstract}
Background: End-of-life discussions rarely begin early in a patient's disease course due to the time intensive nature of these conversations. Neglect of such conversations often results in poor understanding about a patient's care preferences. Electronic health record (EHR)-tethered Personal Health Records (PHRs) are being used more widely in chronic disease management and may provide a time efficient vehicle to embark on early end-of-life conversations, also known as Advance Care Planning (ACP).

Objective: To investigate cultural differences among elderly patients in willingness to engage in electronic ACP communication using EHR-tethered PHRs.

Methods: Qualitative exploratory study. Four focus groups (2 Caucasian Groups and 2 African-American Groups) were conducted, with purposive sampling of patients over 50 years old to represent culturally diverse views on ACP and use of the EHR. Focus groups lasted 60 minutes and were led by 2 consistent co-facilitators. Participants were identified on clinical schedules of an outpatient Midwestern primary care practice over a 30 day period.

Results: Caucasian participants responded more enthusiastically to PHR-based ACP than African-American participants. Discomfort for PHR-based ACP communication stemmed from: lack of computer access; uneasiness with technology; potential loss of human interaction; lack of opportunities for family-centered decision making; and fear of misrepresentation.

Discussion: PHR-based ACP tools may improve delivery, but need individualization for cultural needs of patients. Further investigation is needed to develop tools specific for African-American patients and to reproduce findings in a larger study.
\end{abstract}


Conclusions: In order to ensure applicability to African-American patients, PHR-based ACP tools must incorporate strategies such as: face-to-face interaction; follow-up communication from trusted medical providers; and family engagement.

\section{Key words}

Advance care planning, Personal health records, End-of-life care, Patient communication, Chronic disease

\section{Background}

End-of-life communication is a necessary part of chronic disease management. Early end-of-life discussions help clarify preferences for future medical decisions in the event of health decision-making incapacity ${ }^{[1,2]}$. The process of early, proactive end-of-life communication is known as Advance Care Planning (ACP). ACP helps patients to: (a) reflect on their goals, beliefs, and values; (b) consider future medical treatment preferences; (c) appoint and prepare a surrogate decision-maker; and (d) document their wishes regarding future medical treatment ${ }^{[3]}$. There are a number of favorable outcomes associated with ACP, including: increased satisfaction with care; improved patient quality of life in terminal illness; and better psychological outcomes for family members after patient death ${ }^{[3-5]}$.

Although advance directive (AD) completion rates of up to $70 \%$ have been reported in community dwelling elders, the national prevalence for completed AD among the general population is only $15 \%-25 \%{ }^{[6-8]}$. ACP and AD documentation rates reflected in the medical record are even lower, generally between $5 \%-20 \%$, even in patients with expected survival of less than six months ${ }^{[9-11]}$. An even smaller percentage of minorities participate in this process. African-Americans are $50 \%$ less likely than their Caucasian counterparts to engage in formal, written directives such as a living will ${ }^{[12]}$ and only somewhat less reluctant to participate in informal conversations about ACP ${ }^{[13]}$. More research is needed to understand variables that account for differences in ACP among various population groups.

Nurse-led AD conversations have been shown to increase ACP documentation ${ }^{[14]}$. Outpatient strategies to include and empower registered nurses (RNs) to have ACP conversations with patients need to be further developed ${ }^{[15]}$. Electronic health records (EHRs) have increased collaboration and engagement of RNs in primary care, often making the registered nurse the front line of communication with patients with complex chronic illness ${ }^{[16]}$. Therefore, integrating EHR-based ACP communication into primary care workflows may be a mechanism for increasing registered nurse involvement in the ACP process.

Patients consider ACP initiation to be the physician's responsibility and desire to start this discussion in times of health ${ }^{[17]}$. Routine ACP delivery, however, may not be prioritized by the physician in the time-limited clinical encounter over more urgent competing concerns ${ }^{[18]}$, highlighting: (1) the need for more time efficient methods for recording patient ACP preferences ${ }^{[19]}$ and (2) the need for nursing providers to be integrated into the communication process ${ }^{[15]}$. Employing a team based, registered nurse-centered approach to ACP can help ensure that communication is prioritized. Increasing these strategies has been a large part of the National Institute of Nursing Research's strategic planning statement ${ }^{[20]}$. EHR-tethered Personal Health Record (hereafter referred to as PHR) ACP communication may help overcome barriers and serve as scaffolding for registered nurse-centered, team-based communication ${ }^{[21]}$.

The Medical Library Association/National Library of Medicine Joint Electronic PHR Task Force defined a PHR as "a private, secure application through which an individual may access, manage, and share his or her health information...[It] is not synonymous with the EHR "(pg 244) ${ }^{[22]}$. PHRs allow for ongoing communication between patient and primary care provider. PHRs also aid individuals in taking a more active role in health management and decision-making ${ }^{[5]}$. PHRs make up-to-date, personal health information accessible to patients. This portable accessibility is especially important for patients with complex chronic disease, who are often seen by different care providers ${ }^{[22]}$. Nationally, it is estimated that nearly $78 \%$ of Americans use the internet while $61 \%$ seek health information online ${ }^{[23]}$. PHR-based provider-patient ACP 
communication has the potential to: (1) reach a wide patient audience; (2) maintain ongoing clinical communication contact; and (3) reduce the amount of face-to-face clinical time required for discussions ${ }^{[21]}$. PHR-based ACP communication can use patient-centered language rather than formal legal language typically found in traditional AD forms $^{[12]}$.

Despite the potential benefits of PHR-based ACP communication, disparities exist among patients who currently use PHRs. Populations who experience health disparities are less likely to use PHRs. For example, when compared with Caucasian patients, African-Americans are $50 \%$ less likely to adopt a PHR ${ }^{[24]}$. Other variables beyond race (e.g. limited education, lower socioeconomic status, and limited electronic connectivity) may contribute to some of these findings. These suppositions highlight the need for additional research on variables accounting for differences in both ACP and PHR use, especially in the context of national initiatives to bolster use of PHRs for a variety of health maintenance and planning purposes ${ }^{[12,18,24]}$.

Differences in ACP completion rates and PHR use emphasize the need to develop PHR-based ACP to integrate African-American patient opinions and perspectives. These perspectives can be subsequently applied to other arenas of PHR communication to improve PHR engagement of vulnerable populations.

The purpose of this study was to qualitatively examine differences in Caucasian and African-American opinions toward a PHR-delivered ACP tool. These opinions were assessed through focus groups investigating willingness to use PHR-based ACP communication. The authors' goal was to inform the creation of culturally sensitive, electronic ACP communication tools to be employed in a primary care setting.

\section{Methods}

The study was approved by the Ohio State University Institutional Review Board.

Patients over the age of 50 years old were identified on the clinical schedule at an outpatient primary care practice located within the a large Midwestern medical center over a 30 day period. These patients were then systematically approached for participation during their office visit by a study recruiter. For those who consented to participate, the recruiter gave them the information about where and when the focus group would take place. Twenty-four to 48 hours before their respective focus group was to be held, a reminder phone call was placed to each patient who had agreed to attend. Focus group recruitment was purposive (with consented patients assigned to either African-American or Caucasian focus groups) in order to elicit distinct African-American and Caucasian perceptions and avoid any diffusion of opinions from one ethnic group to the other; participants were selected to represent culturally diverse views on ACP and use of the EHR. Recruitment for each focus group stopped when the group reached a capacity of 5 participants. This number was informed by a preliminary literature review which indicated this to be the ideal number of participants so that opinions and thoughts could be shared equally among participants ${ }^{[25-27]}$. Four total focus groups were conducted, 2 Caucasian (2 groups of 4 participants) and 2 African-American (one group of 4 participants and one group of 2 participants). Although patients of other ethnicities were approached for recruitment, none consented to participate in the study.

To maintain continuity, all focus groups were led by the same pair of co-facilitators, one facilitator was Caucasian and the other was Asian. Both co-facilitators had previously lead focus groups and were guided in the discussion by the same set of questions for each focus group. An African-American physician from the clinic was present during the African-American focus groups. The physician was not asked to facilitate, but was present to help minimize any influence of not having an African-American facilitator.

Prior to the start of each focus group, demographic information and informed consent were obtained from each participant by the study coordinator. While the study coordinator did not participate in the discussion or facilitation, the study 
coordinator did take detailed notes about the focus group in the event that a recording did not work properly or was damaged. Focus Groups took place on weekday evenings after clinic hours in the main waiting area of the clinic from which the participants were recruited. Focus Groups were conducted here because it was a location familiar to participants. The focus groups were conducted after hours to: (1) provide the participants with privacy from routine clinical activities; (2) to allow participants with jobs to attend; (3) to allow participants dependent on others for transportation to attend. Snacks and beverages were provided during the focus groups. Participants were mailed a $\$ 25$ grocery gift card as compensation for their time. Educational information about ACP and PHRs were provided to participants in oral and written format at the beginning of the session. Patients were shown a video about ACP and given a brochure about MyChart, the institution's PHR, supported by the Epic EHR system. Educational materials, including the institution's AD information packet, were presented in a binder distributed to each participant. The binder also contained a copy of discussion questions and excerpts of ACP language employed in validated delivery systems ${ }^{[2,25,28]}$. After these materials were presented, discussion was initiated using a semi-structured format.

Table 1. Focus group discussion questions

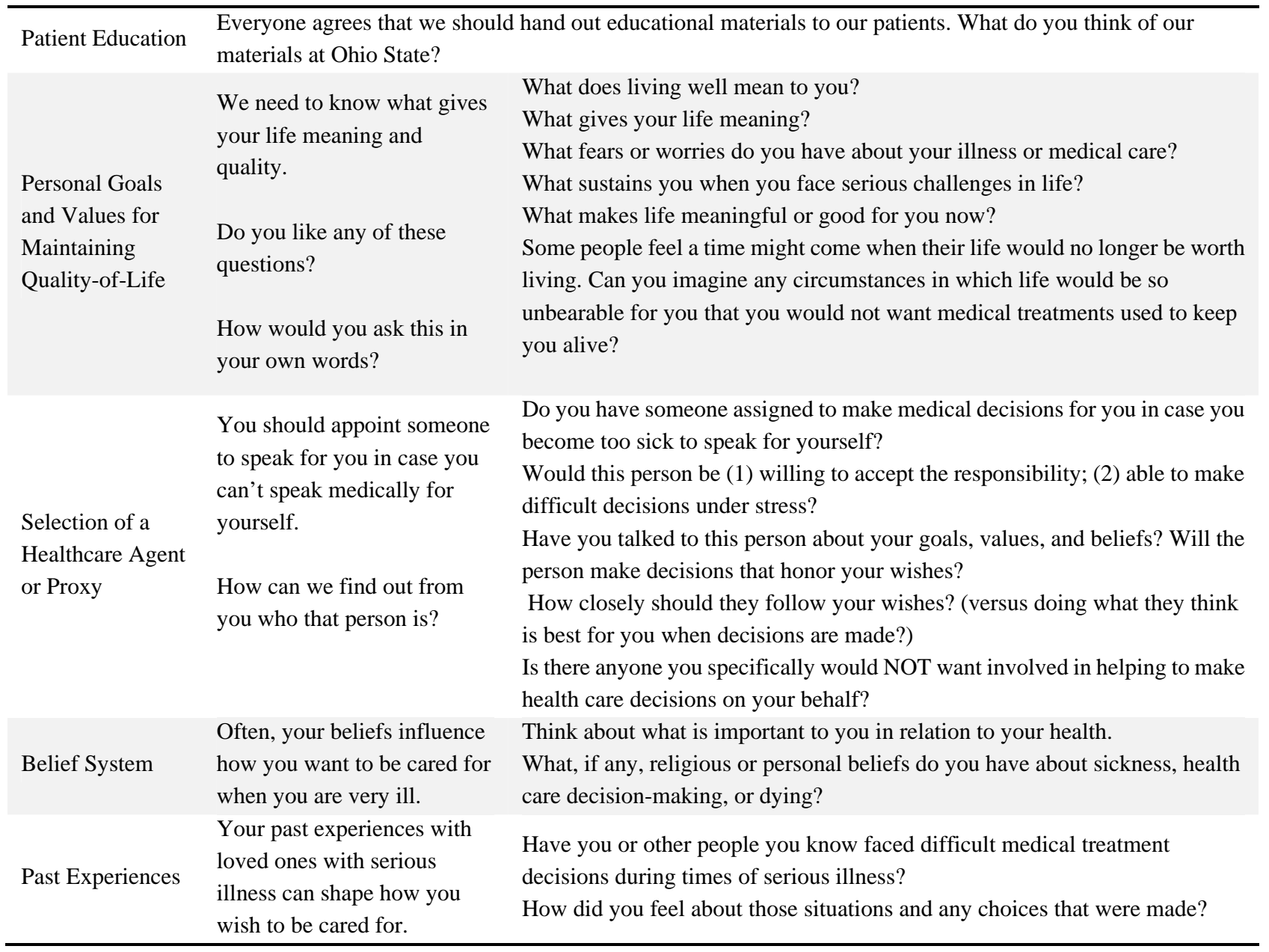

Each discussion lasted approximately 60 minutes and explored patient preferences for electronic ACP communication and desired structure of a PHR communication tool. Discussion from all groups resulted in robust conversations with all members contributing to the discussion, with exception of one Caucasian participant in the first Caucasian focus group who was noted to be less vocal and participatory than others in the group.

The discussion began with an introduction of the facilitators and a reminder of the discussion topic. Participants were reminded that the discussion was confidential and to refrain from using any identifying information in the conversation 
because it was being recorded. The discussion followed a semi-structured format; the same questions were asked during each focus group (see Table 1). This format allowed participants to freely discuss the subject matter and share experiences, thoughts, or opinions.

Data were collected through audio recordings of the focus groups, which were then transcribed using detailed transcription (a transcription method that records not only verbal content, but conversational features such as pauses, stuttering, and interruptions). All focus group recordings were transcribed by the same trained transcriptionist. Study researchers discussed the format of detailed transcription before transcription took place. Notes were also taken at the time of the focus group by the study coordinator. Focus Group 1 was only partially transcribed due to corruption of the audio recording. For this focus group, a scribe's handwritten notes were reviewed to identify discussed themes instead of the detailed transcripts.

Qualitative data was analyzed using techniques of discourse analysis, conversation analysis, and micro-interlocuter analysis. Each method was used in order to obtain different information from the discussion pertinent to the goals of the study; discourse analysis was used to determine the level of comfort that focus groups participants exhibited while discussing the topic; conversation analysis and micro-interlocuter analysis were used to determine the content and themes present in the conversations ${ }^{[26,27,29,30]}$. Several measures to ensure confirmability and credibility of findings were completed. Detailed transcripts were coded alongside field notes by 3 independent coders to establish inter-rater reliability. Each coded the transcript separately, and then came together to compare results from the independent coding. The three coders were study personnel representing three distinct disciplines; medicine, biological sciences and public health. Focused tape review was conducted to verify the accuracy of detailed transcripts and assess intonation. Themes found to be common between the 3 independent coders were summarized. In order to ensure narrative validity, two different researchers (one qualitative researcher with a background in nursing and an expertise in shared decision making and another researcher with an expertise in linguistics, separately reviewed focus group materials and corresponding summaries). In addition, summaries were verified after review of original transcripts by a linguist. Additional peer debriefing was conducted with 2 members of the research team to ensure credibility of findings.

\section{Results}

\subsection{Demographics}

A total of 19 subjects were recruited to four different focus groups, 2 Caucasian and 2 African-American. While attempts were made to recruit 5 participants to each of the four focus groups, due to time and scheduling constraints, only 4 participants were able to be recruited to one of the African-American focus groups. Of the 19 subjects recruited, 6 were 'no shows' for their respective focus groups (2 Caucasian and 4 African-American), leaving 13 total participants. Of those participants, 5 were African-American and 8 were Caucasian. The two Caucasian groups consisted of 5 and 4 members each while the two African-American focus groups consisted of 4 and 2 members each. All participants were made aware of the time and date of the focus group prior to their agreement to participate. All participants were given reminder phone calls 24-36 hours before their respective focus groups to minimize the number of "no-shows".

Ages among the groups ranged from 56-85 years, with a median age of 67. Education level among the participants varied, but no participants who consented to participate in the study had less than a high school diploma. Three participants had completed high school, 3 had completed some college, 1 had a technical degree, 4 had a 4-year college degree, and 2 had a graduate degree. Six of the 13 participants reported having completed a written AD; none of the participants with a completed AD were African-American. Nine reported having home internet access; and 4 reported having a 'smartphone'. Eight participants reported having active PHR (MyChart) accounts; 6 of these participants were Caucasian and 2 were African-American (see Table 2). 
Table 2. Demographic Data for Focus Group Participants (by Race)

\begin{tabular}{lllllllll}
\hline $\begin{array}{l}\text { Focus Group } \\
\text { Participant } \\
\text { Race }\end{array}$ & $\begin{array}{l}\text { Number of } \\
\text { Participants }\end{array}$ & Gender & $\begin{array}{l}\text { Median } \\
\text { age }\end{array}$ & $\begin{array}{l}\text { Home } \\
\text { Internet } \\
\text { Access }\end{array}$ & $\begin{array}{l}\text { Completed } \\
\text { AD }\end{array}$ & $\begin{array}{l}\text { Active } \\
\text { MyChart } \\
\text { Account }\end{array}$ & $\begin{array}{l}\text { Average } \\
\text { Number of } \begin{array}{l}\text { Average } \\
\text { Active } \\
\text { Problemser of }\end{array} \\
\text { prescription } \\
\text { medications }\end{array}$ \\
\hline $\begin{array}{l}\text { Caucasians } \\
\text { African }\end{array}$ & 8 & $\begin{array}{l}\text { Female 5/8 } \\
\text { Male 3/8 }\end{array}$ & 67 & $6 / 8$ & $6 / 8$ & $6 / 8$ & 10 & 5 \\
$\begin{array}{l}\text {-American } \\
\text { Total }\end{array}$ & 5 & $\begin{array}{l}\text { Female- } 4 / 5 \\
\text { Male- } 1 / 5\end{array}$ & 69 & $3 / 5$ & $0 / 5$ & $2 / 5$ & 13 & 9 \\
Total & 13 & $\begin{array}{l}\text { 9 Female } \\
\text { 4 Male }\end{array}$ & 69 & $9 / 13$ & $6 / 13$ & $8 / 13$ & 11 & 7 \\
\hline
\end{tabular}

\subsection{Focus group summaries}

\subsubsection{Caucasian focus groups}

Six of eight Caucasian participants reported that they had completed an AD. All those who completed AD were aided by attorneys, and only one participant had explicitly discussed the AD with a physician. Although participants endorsed some discomfort with end-of-life experiences and discussions, they generally seemed comfortable with ACP discussion because a majority of them had experienced the death of loved ones. Participants felt that discomfort with ACP conversations was driven by the physician's unwillingness to engage in ACP, not the patient unwillingness to discuss the topic. Participants voiced that completing different kinds of ADs were complicated; they felt that electronic communication could simplify the ACP documentation process (See Tables 3 \& 4).

As a whole, participants were enthusiastic about using MyChart for ACP. Some of the reasons cited for approving of MyChart in ACP were ease of use, the ability to clearly share information with care providers and loved ones, and documentation of their wishes in their own words.

Participants did vary in preferred format of MyChart based ACP. Whereas some preferred opportunities for unstructured reflection, others felt that only essential elements of ACP should be included in the communication framework and preferred that questions about future care decisions be condensed into small messages (See Tables 3 \&4).

\subsubsection{African-American focus groups}

None of the participants in either focus group reported completing a written AD or having communicated with their medical provider about ACP or AD. Some participants reported feeling personal discomfort in broaching the topic of end-of-life care. Although participants believed it was important to engage in ACP conversations with providers, participants differed as to whether patients or physicians should start ACP conversations, and they were unsure how providers and patients should ideally broach these conversations. Some participants had talked with family or loved ones about wishes for future care, but had yet to write them down, whereas other participants faced resistance when attempting to engage in discussions about future care.

Participants indicated that they would be willing to try a system like MyChart for the purpose of ACP, but issues such as limited internet connectivity or fearing loss of personal interaction with the physician were potential barriers to use. Participants also explained that they needed human interaction to supplement electronic communication in order to ensure their comments were not misunderstood. One participant noted that she might delete important messages if they did not appear to be from a trusted source. They valued the potential of MyChart communication in ACP to allow thought and reflection. Participants reported that they would be more likely to engage in MyChart communication for ACP if loved ones, such as children, could access the tool with them in a proxy or collaborative capacity (See Tables $3 \& 4$ ). 
Table 3. Similarities between Caucasian and African-American participants

Similarites

Need for ACP Communication

Desire for Physician Feedback

Facilitating a Complex Process

Personal Experiences Influence ACP Opinions

\section{Support Quotes}

"Personally, um, I think that I would just need the um like the living will and um, because I've, I've, I've already begun talking to my family about if something happens to me and I can't speak for myself... So I guess it's, it's [clearing throat] more of putting it down on paper so that no one forgets or whatever.” (African-American participant, Focus Group 4’ pg2)

"You certainly need to have that conversation with your doctor and your significant others."

(Caucasian participant Focus Group 3, pg 4)

"It seems to me that the um, your previous experiences will certainly influence and probably inform the choices you have. And if you're having a discussion with your caregiver-with your doctor, any problems, issues, or even suc-successes that are in your experience, probably want to be discussed with the doctor” (African-American participant, Focus Group 4, pg 16)

"Also, the doctors, or the health providers or even nurses could talk to the patient and ask if they would like some more information just like you suggested.” (Caucasian participant, Focus Group 3,pg 4 )

"I mean, it's a complex - it can be a very complex deal. It might be real simple, but could be very complex. But I already know how I feel about the POA and the living will. So boy I'd like to get those just off my plate and done right now. As you said, it took us at least two years to get through that process." (Caucasian Participant, Focus Group 3, pg 6)

"Or if they come back to the next day follow-up visit, they could take it home with them bring it back with them. But why would I do that? Or if they want to talk beforehand have the doctor talk about it”

(African-American participant, Focus Group 1,pg 2)

"Uh, I have one child who-who thinks she should just fight on and fight on and fight on. And um, I, that, it really worries me that when my time comes that she, she may be a problem. [slight chuckle] Ah, I think the others will be fine with my choices, but she might be difficult. But we'll talk about that later I bet.” (Caucasian Participant, Focus Group 3, pg 6)

"What prompted mine, me talking to my family about it, was uh, well, my father died in '92. And so, and I just thought his funeral was like kinda crazy [slight chuckle], you know, relatives-wise, and so then I started talking about how I want things at that point”

(African-American participant, Focus Group 4, pg 2) 
Table 4. Differences between Caucasian and African-American participants

\begin{tabular}{|c|c|}
\hline Differences & Supporting Quotation \\
\hline $\begin{array}{l}\text { Enthusiasm vs. Suspicion About PHR } \\
\text { Use in the ACP Process }\end{array}$ & $\begin{array}{l}\text { "I think using the MyChart correspondence because it’s so simple and it’s easy to use. If } \\
\text { something pops up, you know, I send to [my physician] a question, and she sends me back } \\
\text { a response and, and it can be used for anything including this kind of process I think.” } \\
\text { (Caucasian participant, Focus Group 1, pg 2) } \\
\text { Vs. } \\
\text { "I have my reservations and fears because so much is done with computers. And they're } \\
\text { used for wonderful things but things too that make me leery when you hear things that go } \\
\text { on. I told you I'm from the cave. I told you that. But I don't know.” (African-American } \\
\text { participant, Focus Group 2, pg 18) }\end{array}$ \\
\hline Willingness to Use PHR & $\begin{array}{l}\text { "I do not own a computer. I have a basic cell phone. I mean, I am just overwhelmed with } \\
\text { computers, you know.” (African-American participant, Focus Group 2, pg 15) } \\
\text { Vs. } \\
\text { "[Security issues] were actually [there] even before even MyChart was there, but I don't } \\
\text { have those concerns. It’s no less secure to me than a piece of paper sitting back there that } \\
\text { ten different staff members can see. (Caucasian participant, Focus Group 3, p 18) }\end{array}$ \\
\hline $\begin{array}{l}\text { Effect of PHR Communication on } \\
\text { Provider-Patient Relationship }\end{array}$ & $\begin{array}{l}\text { "Absolutely. But I mean, it's, it's good, I mean, this is wonderful in its place, but there's } \\
\text { nothing like people meeting one another and you see that, you see a face and you } \\
\text { experience that person, you know.”(African-American participant, Focus Group 4, pg 19) } \\
\text { Vs. } \\
\text { "I wouldn't expect the doctor or the nurse or the physician assistant to take the time and to } \\
\text { go through all of this [ACP], but they could identify the people, then maybe they could use } \\
\text { MyChart to communicate with them...” (Caucasian participant, Focus Group } 2 \text { pg 3) }\end{array}$ \\
\hline
\end{tabular}

\subsection{Analysis summaries}

Our analyses supported the separation of information by race/ethnicity, demonstrating some similarities but important differences between the Caucasian and African-American participants.

\subsubsection{Analysis summary of Caucasian focus groups}

In general, participants responded enthusiastically to the idea of using MyChart for ACP. Many felt that because MyChart was easy to use for other purposes, using it for ACP would also be easy. Although the majority of the participants thought talking with their care provider about ACP were important, few had done so. However, many had consulted legal advice in completing AD. Most participants expressed a strong desire to clearly communicate individual wishes for future care to loved ones and health care providers with the expectation that wishes would be honored. Participants seemed generally at ease with discussing end-of-life experiences over MyChart because they could accurately display their personal wishes in their own words.

"If you send out these questions by MyChart, I have time on my own to think about what my answers should be. There should not be a word limit either."

However, this level of comfort was not universal, as evidenced by one withdrawn, less communicative participant.

Note from scribe: One participant was very quiet during discussion- mentioned that she had not prepared any ACP documents but had conversations with her daughter. She had once activated MyChart, but was not sure how to use it. 


\subsubsection{Analysis summary of African-American focus groups}

Participants were generally cautious of using MyChart for ACP; reasons included lack of computer access, discomfort with technology, and potential loss of human interaction. Participants valued being known by the health care provider, and many feared that electronic communication would cause misrepresentation. Participants seemed somewhat uncomfortable discussing end-of-life care in the health care setting. Many wanted integral family and trusted health care provider inclusion in MyChart communication and ACP discussions.

"There is nothing like people meeting each other. You see a face and experience the person. [For MyChart to work] it would be better if it were a part of the discussion, not the sole part."

"So much goes on with computers that I have fears and reservations about them. There are wonderful things and not so wonderful things.”

\section{Discussion}

\subsection{Discussion}

PHR-based ACP could serve as a valuable tool in order to provide patient-centered care and reduce unwanted healthcare interventions. While our study suggests that this type of tool would be acceptable to some patients, our findings also suggest that there will be some racial and ethnic differences in acceptability. Further, our results point out that it will be important that any electronic ACP discussions be closely accompanied by face-to-face interaction, close communication from the care provider, and integration of co- or proxy decision makers, especially with African-American patients.

Current literature suggests that African-Americans, when asked about future treatment preferences, generally prefer more aggressive care plans than Caucasians in chronic disease and advanced illness ${ }^{[31-34]}$. Additionally, several studies indicate that African-Americans are much less likely to use hospice services than Caucasians ${ }^{[32-35]}$. Although major differences in care preferences have been reported, African-American patients engage less frequently in discussions to voice care preferences ${ }^{[31]}$. The cultural factors for limited engagement in ACP conversations remain poorly understood ${ }^{[33,36,37]}$, even though communication about developing end-of-life care plans must be individualized ${ }^{[38]}$. ACP ensures that patient preferences at the end-of-life are well-informed and honored; yet, racial minorities with advanced illness are disadvantaged compared to their Caucasian counterparts ${ }^{[32]}$. Continued investigation beyond this study is required to incorporate African-American patient communication preferences into novel ACP strategies.

Review of PHR literature consistently demonstrates reduced use by non-whites. For example, Kahn demonstrated that patients who used a PHR based safety net program for HIV were more likely to be male, Caucasian, and non-Hispanic ${ }^{\text {[39] }}$. Numerous studies from varied health systems have demonstrated that African-American patients have lower odds of activating, logging on, and using PHR ${ }^{[24,40,41]}$ than Caucasians. These studies all concluded that despite the promise of PHR in improving chronic disease management, its use has the potential to increase existing communication health disparities between Caucasians and African-Americans. However, African-American patients have reported belief that PHR use would improve personal health care understanding ${ }^{[42]}$. Strategies such as coupon incentives for groceries, kiosks, ${ }^{[43]}$ and family engagement ${ }^{[44]}$ have improved African-American engagement of PHR, suggesting that barriers to African-American PHR use are not insurmountable. Although not discussed in our focus groups specifically, research suggests that PHR-based communication for ACP for African-American patients would likely need more marketing and incentives for use than for Caucasian patients in order to overcome voiced concerns.

\subsection{Study limitations}

This study had a relatively small number of patients involved in the focus groups. While a satisfactory number of patients were initially recruited to participate, there were a large number of "no shows", particularly in the African-American 
groups. One factor that may have influenced African-American participation is recruitment by a Caucasian study recruiter. The study's qualitative design with purposive sampling and small sample size have limited the ability to determine whether race was the primary factor in driving perceptions about PHR-based ACP communication. The strength of such conclusions could be improved if replicated in additional focus groups or through surveys in a representative sample.

The corruption of the audio recording of the first group (a Caucasian focus group) limited the detailed analysis of the recording and transcription. While notes were transcribed during the discussion, the corruption of the recording before complete transcription did not allow for more in-depth analysis of the conversation.

Although all focus group participants had completed high school, represented groups were not the same with respect to educational level, home internet connectivity, MyChart use, and AD completion. The demographic differences between the Caucasian and African-American groups likely influence reported perceptions in ways that are difficult to quantify.

Ideally an African-American co-facilitator would have been present in order to minimize any influence on conversation as it is possible that African-American participants may have connected more with someone of their own race.

\section{Conclusions}

Addressing patient-reported barriers to using PHR in the context of ACP may result in generalizable strategies for improving other electronic chronic disease management communication for African-American patients. Our work suggests that strategies such as family integration, clinic on-site connectivity, and face-to-face support may result in more appealing PHR applications for African-American patients.

As PHR use increases in the outpatient setting, it provides an innovative mechanism to potentially improve ACP care delivery ${ }^{[21]}$. However, just as face-to-face ACP discussions must be tailored to meet patient needs, PHR-based ACP must be individualized in order to be effective. Limited investigation has been conducted on the effectiveness of PHR based ACP communication. Our findings suggest that different PHR delivery formats for African-American and Caucasian patients in our population could help encourage use.

Increasing the use of such a tool can better involve RNs in communication because much of the PHR-based interactions are filtered through RNs. This data is being used to develop an RN- centered PHR communication tool for the outpatient environment that is culturally sensitive to both Caucasian and African-American patients.

These findings can help guide and inform design of PHR-delivered ACP intervention tools for use in outpatient clinical practice, especially primary care. Such interventions must be culturally relevant to patients from many cultures and also made accessible to patients who have limited internet connectivity/ experience or increased reliance on family caregivers for communication. The growing use of EHR/ PHR makes it imperative that all patients, regardless of race or connectivity, have workable mechanisms to engage providers in electronic communication, including discussion about ACP. Further investigation is needed to understand how to adapt developed clinical tools to improve usability not only in African-American patients, but also those with limited connectivity.

\section{Acknowledgements}

We would like to thank the following people for their support over the course of the study: Taylor Pressler, MS, Ohio Health, Columbus, OH, U.S.A.; Rober Taylor, MD, Division of Palliative Care, Department of Internal Medicine, College of Medicine, Ohio State University; Barbara Longo, Patricia Strickland, and Ann Henry, OSU Internal Medicine and Pediatrics Grandview for their administrative support of the project; Rose Hallarn, OSU Center for Clinical and Translational Science for her assistance with participant recruitment strategies; Peter Embi for his advising on managing an Epic-based interdisciplinary study; Lori Blum, Grants Administration for her assistance in budgetary matters. The 
project described was supported by Award Number Grant 8UL1TR000090-05 from the National Center for Advancing Translational Sciences. The content is solely the responsibility of the authors and does not necessarily represent the official views of the National Center for Advancing Translational Sciences or the National Institutes of Health.

\section{Reference}

[1] Curd PR, Advance care planning reconsidered: toward an operational definition of outpatient advance care planning. J Palliat Med. 1999; 2(2): 157-9. PMid:15859812 http://dx.doi.org/10.1089/jpm.1999.2.157

[2] Levi BH, Green MJ, Too soon to give up: re-examining the value of advance directives. Am J Bioeth. 2010; 10(4): 3-22. PMid:20379910 http://dx.doi.org/10.1080/15265161003599691

[3] Detering KM, Hancock AD, Reade MC,and Silvester W, The impact of advance care planning on end of life care in elderly patients: randomised controlled trial. BMJ. 2010; 340: c1345. PMid:20332506 http://dx.doi.org/10.1136/bmj.c1345

[4] Heyland DK, et al. Discussing prognosis with patients and their families near the end of life: impact on satisfaction with end-of-life care. Open Med. 2009; 3(2): e101-10. PMid:19946391

[5] Zhang B, et al, Health care costs in the last week of life: associations with end-of-life conversations. Arch Intern Med. 2009; 169(5): 480-8. PMid:19273778 http://dx.doi.org/10.1001/archinternmed.2008.587

[6] Salmond SW, David E, Attitudes toward advance directives and advance directive completion rates. Orthop Nurs. 2005; 24(2): 117-27; quiz 128-9. PMid:15902009 http://dx.doi.org/10.1097/00006416-200503000-00007

[7] Silveira MJ, Kim SY, Langa KM, Advance directives and outcomes of surrogate decision making before death. N Engl J Med. 2010; 362(13): 1211-8. PMid:20357283 http://dx.doi.org/10.1056/NEJMsa0907901

[8] Teno JM, Gruneir A, Schwartz Z, Nanda A, and Wetle T, Association between advance directives and quality of end-of-life care: a national study. J Am Geriatr Soc. 2007; 55(2): p. 189-94. PMid:17302654 http://dx.doi.org/10.1111/j.1532-5415.2007.01045.x

[9] Temel JS, et al. Early palliative care for patients with metastatic non-small-cell lung cancer. N Engl J Med. 2010; 363(8): p. 733-42. PMid:20818875 http://dx.doi.org/10.1056/NEJMoa1000678

[10] Bradley NM, Sinclair E, Danjoux C, et al. The do-not-resuscitate order: incidence of documentation in the medical records of cancer patients referred for palliative radiotherapy. Curr Oncol. 2006; 13(2): 47-54. PMid:17576441

[11] Teno JM, Licks S, Lynn J, et al., Do Advance Directives Provide Instructions That Direct Care? Support Investigators. Study to Understand Prognoses and Preferences for Outcomes and Risks of Treatment. Journal of the American Geriatric Society. 1997; 45(4): 508-512. PMid:9100722

[12] Gerst K and Burr JA, Planning for End-of-Life Care: Black-Caucasian Differences in the Completion of Advance Directives. Research on Aging. 2008; 30(4): 428-449. http://dx.doi.org/10.1177/0164027508316618

[13] Hopp FP, Duffy SA, Racial variations in end-of-life care. J Am Geriatr Soc. 2000; 48(6): 658-63. PMid:10855602

[14] Hinderer KA, Lee MC. Assessing a nurse-led advance directive and advance care planning seminar. Appl Nurs Res. 2014; 27(1): 84-6. PMid:24290237 http://dx.doi.org/10.1016/j.apnr.2013.10.004

[15] Jeong SY, Higgins I, McMillan M. Experiences with advance care planning: nurses' perspective. Int J Older People Nurs. 2011; 6(3): 165-75. http://dx.doi.org/10.1111/j.1748-3743.2009.00200.x

[16] Chunchu K, et al. A patient centered care plan in the EHR: improving collaboration and engagement. Fam Syst Health. 2012; 30(3): 199-209. PMid:22866953 http://dx.doi.org/10.1037/a0029100

[17] Johnston SC, Pfeifer MP, McNutt R. The discussion about advance directives. Patient and physician opinions regarding when and how it should be conducted. End of Life Study Group. Arch Intern Med.1995; 155(10): 1025-30. PMid:7748044 http://dx.doi.org/10.1001/archinte.1995.00430100047005

[18] Mercer SW, Watt GC. The inverse care law: clinical primary care encounters in deprived and affluent areas of Scotland. Ann Fam Med. 2007; 5(6): 503-10. PMid:18025487 http://dx.doi.org/10.1370/afm.778

[19] Aronsky D, et al. Electronic screening of dictated reports to identify patients with do-not-resuscitate status. J Am Med Inform Assoc. 2004; 11(5): 403-9. PMid:15187069 http://dx.doi.org/10.1197/jamia.M1518

[20] National Institue of Nursing Research, Building Momentum: The Science of End-of-Life and Palliative Care, 1997-2010. National Institue of Health: Bathesda, Maryland; 2013.

[21] Bose-Brill S, Pressler TR, Commentary: opportunities for innovation and improvement in advance care planning using a tethered patient portal in the electronic health record. J Prim Care Community Health. 2012; 3(4): 285-8. PMid:23804174 http://dx.doi.org/10.1177/2150131911435525

[22] Jones DA, et al. Characteristics of personal health records: findings of the Medical Library Association/National Library of Medicine Joint Electronic Personal Health Record Task Force. Journal of the Medical Library Association. 2010; 98(3): 243-249. 
PMid:20648259 http://dx.doi.org/10.3163/1536-5050.98.3.013

[23] Kaelber DC, et al. A research agenda for personal health records (PHRs). Journal of the American Medical Informatics Association. 2008; 15(6): 729-736. PMid:18756002 http://dx.doi.org/10.1197/jamia.M2547

[24] Yamin CK, et al. The digital divide in adoption and use of a personal health record. Arch Intern Med. 2011; 171(6): 568-74. PMid:21444847 http://dx.doi.org/10.1001/archinternmed.2011.34

[25] Karel MJ, Powell J, Cantor MD, Using a Values Discussion Guide to facilitate communication in advance care planning. Patient Educ Couns. 2004; 55(1): 22-31. http://dx.doi.org/10.1016/S0738-3991(03)00246-5

[26] Onwuegbuzie AJ, Dickinson WB, Leech NL, Zoran AG. A Qualitative Framework for Collecting and Analyzing Data in Focus Group Research Inernational Journal of Qualitative Methods. 2009; 8(3): 1-21.

[27] Wilkinson S. Focus groups in health research: exploring the meanings of health and illness. J Health Psychol. 1998; 3(3): 329-48. PMid:22021395 http://dx.doi.org/10.1177/135910539800300304

[28] Hammes BJ, Rooney BL, Gundrum JD, A comparative, retrospective, observational study of the prevalence, availability, and specificity of advance care plans in a county that implemented an advance care planning microsystem. J Am Geriatr Soc. 2010; 58(7): 1249-55. PMid:20649688 http://dx.doi.org/10.1111/j.1532-5415.2010.02956.x

[29] Potter J andWetherell M. Discourse and social psychology : beyond attitudes and behaviour. Newbury Park. Calif: Sage Publishing. 1987.

[30] Drew P, Chatwin J, Collins S, Conversation analysis: a method for research into interactions between patients and health-care professionals. Health Expect. 2001; 4(1): 58-70. PMid:11286600 http://dx.doi.org/10.1046/j.1369-6513.2001.00125.x

[31] Kurella Tamura M, Goldstein MK, Perez-Stable EJ, Preferences for dialysis withdrawal and engagement in advance care planning within a diverse sample of dialysis patients. Nephrol Dial Transplant, 2010; 25(1): 237-42. PMid:19734137 http://dx.doi.org/10.1093/ndt/gfp430

[32] Reynolds KS, et al. End-of-life care in nursing home settings: do race or age matter? Palliat Support Care. 2008 ; 6(1): $21-7$. PMid:18282341 http://dx.doi.org/10.1017/S1478951508000047

[33] Kwak J, Haley WE, Current research findings on end-of-life decision making among racially or ethnically diverse groups. Gerontologist. 2005; 45(5): 634-41. PMid:16199398 http://dx.doi.org/10.1093/geront/45.5.634

[34] Greiner KA, Perera S, Ahluwalia JS, Hospice usage by minorities in the last year of life: results from the National Mortality Followback Survey. J Am Geriatr Soc. 2003; 51(7): 970-8. PMid:12834517 http://dx.doi.org/10.1046/j.1365-2389.2003.51310.x

[35] Lepore MJ, Miller SC, Gozalo P. Hospice use among urban Black and White U.S. nursing home decedents in 2006. Gerontologist, 2011; 51(2): 251-60. PMid:21076085 http://dx.doi.org/10.1093/geront/gnq093

[36] Sudore RL, et al. Uncertainty about advance care planning treatment preferences among diverse older adults. J Health Commun. 2010; 15 Suppl 2: 159-71. PMid:20845201 http://dx.doi.org/10.1080/10810730.2010.499982

[37] Johnstone MJ, Kanitsaki O, Ethics and advance care planning in a culturally diverse society. J Transcult Nurs. 2009; $20(4): 405-16$. PMid:19597187 http://dx.doi.org/10.1177/1043659609340803

[38] Curtis JR, et al. Why don't patients and physicians talk about end-of-life care? Barriers to communication for patients with acquired immunodeficiency syndrome and their primary care clinicians. Arch Intern Med. 2000; 160(11): 1690-6. PMid:10847263 http://dx.doi.org/10.1001/archinte.160.11.1690

[39] Kahn JS, et al. Personal health records in a public hospital: experience at the HIV/AIDS clinic at San Francisco General Hospital. J Am Med Inform Assoc. 2010; 17(2): 224-8. PMid:20190069 http://dx.doi.org/10.1136/jamia.2009.000315

[40] Roblin DW, et al. Disparities in use of a personal health record in a managed care organization. J Am Med Inform Assoc. 2009; 16(5): 683-9. PMid:19567790 http://dx.doi.org/10.1197/jamia.M3169

[41] Sarkar U, et al. Social disparities in internet patient portal use in diabetes: evidence that the digital divide extends beyond access. $\mathrm{J}$ Am Med Inform Assoc. 2011; 18(3): 318-21. PMid:21262921 http://dx.doi.org/10.1136/jamia.2010.006015

[42] Patel VN, et al. Low-income, ethnically diverse consumers' perspective on health information exchange and personal health records. Inform Health Soc Care. 2011; 36(4): 233-52. PMid:21851182 http://dx.doi.org/10.3109/17538157.2011.554930

[43] Botts NE, Horan TA, Thoms BP. HealthATM: personal health cyberinfrastructure for underserved populations. Am J Prev Med. 2011; 40(5 Suppl 2): S115-22. PMid:21521584 http://dx.doi.org/10.1016/j.amepre.2011.01.016

[44] Burke RP, et al., Transforming patient and family access to medical information: utilisation patterns of a patient-accessible electronic health record. Cardiol Young. 2010; 20(5): 477-84. PMid:20456816 http://dx.doi.org/10.1017/S1047951110000363 